\title{
Connecting the Commodore 64 to the IBM PC
}

\author{
ELLIOTT J. BONEM and JERRY W. O'DELL \\ Eastern Michigan University, Ypsilanti, Michigan
}

\begin{abstract}
Hardware is described that permits bidirectional transfer of data between the Commodore 64 and an IBM-compatible PC. Commercial terminal programs can be used to transmit data. The hardware, which can be constructed for less than $\$ 15$, opens up several opportunities for making good use of the cost-effective C64 computer.
\end{abstract}

In a recent issue of this journal, Pieper and Lachnit (1989) presented a means of transmitting data from a Commodore 64 to IBM-compatible PCs. The C64 is a particularly useful laboratory controller, especially given its minimal price.

Pieper and Lachnit's (1989) method seems sound, but we propose a simpler and less expensive way to do the job. Most users already have terminal programs for both computers. We use Bobsterm (Lentini, 1985) for the C64, and Procomm (Datastorm, 1986) for the IBM. With such programs in hand, one can simply use the terminal programs to transmit the data. This permits the use of the error-checking features of the terminal programs, and it increases flexibility, allowing, for example, transmission of data from the IBM back to the C64.

The serial port on the IBM accepts the TTL signals from the $\mathrm{C} 64$, and one merely has to connect the receive, transmit, and ground lines between the two units. Generally, however, the C64 TTL signals must be converted to RS232 signals. Mail order units are available to do this job; but they are somewhat expensive, and they may be difficult to obtain.

The circuit shown in Figure 1, which converts the TTL signals to RS232 signals, can be built in $1 \mathrm{~h}$ with parts available from Radio Shack for a cost of less than \$15. Our unit was constructed on a Radio Shack perf board; nothing about the construction is critical. The $-9 \mathrm{~V}$ may be obtained from a 9-V battery if light use is anticipated, or from an old $110-\mathrm{V}$ ac to $9-\mathrm{V}$ dc adapter, as in our case.

This circuit will also allow the C64 to be used with a wide variety of modems, so that, for example, data can be transferred directly to a large mainframe computer.

In a hobbyist's magazine, Rupert (1985) described a similar circuit. Two of his comments seem germane. First, the $+5 \mathrm{~V}$ connected to Pin 14 of the 1488 may at times not supply enough voltage. Should this be the case, another $9-$ or $12-\mathrm{V}$ supply could be connected. Indeed,

Reprints may be obtained from Elliott J. Bonem, Department of Psychology, 537 Mark Jefferson, Eastern Michigan University, Ypsilanti, MI 48197.

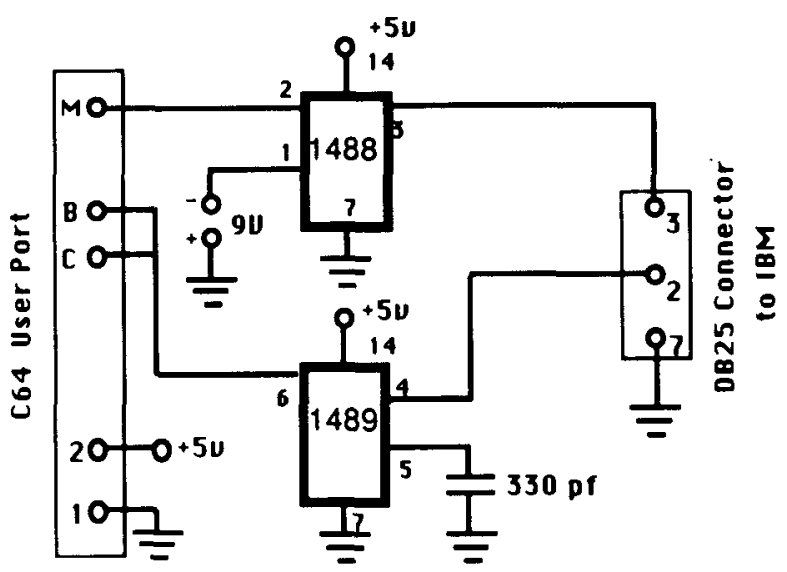

Figure 1. C64 to PC interface circuit. The letters $M, B$, and C refer to user port connections on the $C 64$. The numbers 2, 3, and 7 refer to pin numbers on the DB25 connector, which connects to the PC serial port.

$+12 \mathrm{~V}$ is available in the $\mathrm{C} 64$, although this requires opening the unit. Rupert was also concerned about using only one connection for the ground. On the C64's user port, Pins 1, 12, A, and $\mathrm{N}$ are all at chassis ground and could all be connected. We have used the circuit shown in Figure 1 many times without any difficulty, but the reader should be aware of these potential problems.

\section{REFERENCES}

Datastorm Technologies. (1986). Procom [User supported computer program]. Columbia, MO: Author.

Lentini, R. (1985). Bobsterm Pro [Computer program]. Denver, CO: Progressive Peripherals and Software.

PiePer, W., LACHNIT, H. (1989). C64-to-PC: Transmitting data from a Commodore C64 to IBM-compatible PCs. Behavior Research Methods, Instruments, \& Computers, 21, 653.

RUPERT, D. (1985, December). The IBM Connection. Ahoy, pp. 61$62,114-117,126-127$

(Manuscript received March 5, 1990; revision accepted for publication April 30, 1990.) 